\title{
Electrochemical bacterial detection using poly(3-aminophenylboronic acid)-based imprinted polymer.
}

Mohsen Golabi, Filiz Kuralay, Edwin Jager, Valerio Beni and Anthony Turner

\section{Journal Article}

\section{Tweet}

N.B.: When citing this work, cite the original article.

Original Publication:

Mohsen Golabi, Filiz Kuralay, Edwin Jager, Valerio Beni and Anthony Turner, Electrochemical bacterial detection using poly(3-aminophenylboronic acid)-based imprinted polymer., Biosensors \& bioelectronics, 2016.

http://dx.doi.org/10.1016/j.bios.2016.09.088

Copyright: Elsevier

http://www.elsevier.com/

Postprint available at: Linköping University Electronic Press

http://urn.kb.se/resolve?urn=urn:nbn:se:liu:diva-133647

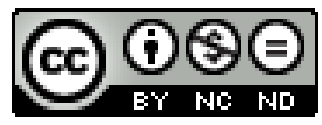




\title{
Electrochemical bacterial detection using poly (3- aminophenylboronic acid)-based imprinted polymer
}

\author{
Mohsen Golabi ${ }^{1}$, Filiz Kuralay², Edwin W H Jager ${ }^{1}$, Valerio Beni ${ }^{\$ \$}$, Anthony P F Turner ${ }^{1^{*}}$ \\ ${ }^{1}$ Biosensors and Bioelectronics Centre, IFM, Linköping University, Linköping, Sweden. \\ ${ }^{2}$ Department of Chemistry, Faculty of Arts and Sciences, Ordu University, Ordu, Turkey \\ \$Current affiliation: Acreo Swedish ACT AB, Norrköping, Sweden
}

\begin{abstract}
Biosensors can deliver the rapid bacterial detection that is needed in many fields including food safety, clinical diagnostics, biosafety and biosecurity. Whole-cell imprinted polymers have the potential to be applied as recognition element in biosensors for selective bacterial detection. In this paper, we report on the use of 3-aminophenylboronic acid (3-APBA) for the electrochemical fabrication of a cell-imprinted polymer (CIP). The use of a boronic acid group bearing monomer with its ability to specifically interact with cis-diol allowed the formation of a polymeric network presenting both morphological and chemical recognition abilities. A particularly beneficial feature of the proposed approach is the reversibility of the cis-diol-boronic group complex, which facilitates easy release of the captured bacterial cells and subsequent regeneration of the CIP. Staphylococcus epidermidis was used as the model target bacteria for the CIP and electrochemical impedance spectroscopy (EIS) was explored for the label-free detection of the target bacteria. The modified electrodes showed a linear response over the range of $10^{3}-10^{7}$ $\mathrm{cfu} / \mathrm{mL}$. A selectivity study also showed that the CIP could discriminate its target from nontarget bacteria having similar shape. The CIPs had high affinity and specificity for bacterial detection and provided a switchable interface for easy removal of bacterial cell.
\end{abstract}

Keywords: 3-Aminophenylboronic acid, whole-cell imprinted polymers, electrochemical impedance spectroscopy, label-free detection, Staphylococcus epidermidis.

*Corresponding author: Anthony P F Turner 


\section{Introduction}

Early stage detection and identification of pathogens are key concerns since infections have an enormous impact on social health and the global economy (Allos et al. 2004). Although conventional culture-based approaches are accurate and reliable, they are costly, requiring wellequipped laboratories and trained people, and lengthy procedures. Unfortunately, delays in results are still responsible for significant number of mortalities and morbidities, and hence there is a need for faster, cost-effective and arguably decentralised analytical methods. This need led to the development of several new approaches based on genetic analysis (Call et al. 2003; Kemp et al. 2010; Zhou 2003) and affinity assays based on antibodies or peptides (Dover et al. 2009; Skottrup et al. 2008; Yoo and Lee 2016). Unfortunately, the use of antibodies has a significant drawback due to their relatively poor stability and limited operational conditions. In order to overcome these limitations, the development and application of synthetic receptors such as aptamers (Bagheryan et al. 2016; Özalp et al. 2013; Sheikhzadeh et al. 2016) and molecularly imprinted polymers (MIPs) has been explored.

MIPs are polymers that are fabricated via chemical, photochemical or electrochemical methods in the presence of a target template material of interest (Sharma et al. 2012; Uzun and Turner 2016). This process results in the fabrication, following removal of the template, of polymeric structures containing cavities, complementary in shape and chemical properties with the template itself (Uzun and Turner 2016; Whitcombe et al. 2014). MIPs have found wide application in several areas including sensing and separation of small molecules (Schirhagl 2014), bio-

macromolecules (Iskierko et al. 2016) and even larger analytes such as whole cells (Dickert and Hayden 2002; Namvar and Warriner 2007; Yilmaz et al. 2015). The simplicity of the fabrication 
process together with their stability and cheapness makes MIPs attractive as artificial recognition elements for use in biosensors (Uzun and Turner 2016). Reports on cell-imprinted polymers (CIPs), MIPs obtained using whole cells as template, have been recently started to appear for various applications including in microbial fuel cells (Lee et al. 2015a), for specific cell capture, cell-sorting, separation (Schirhagl et al. 2012a) and detection (Cohen et al. 2010; Lee et al. 2015b; Lee et al. 2015c). Stamping and casting methods have been the most widely reported approaches for whole-cell imprinting (Aherne et al. 1996; Qi et al. 2013; Ren and Zare 2012; Schirhagl et al. 2012b), but more recently the use of electrochemical polymerisation (EC) has been demonstrated. Rapid bacteria detection using a QCM (quartz crystal microbalance) was reported by using electrochemically fabricated overoxidised polypyrrole CIP film on gold electrode. (Le et al. 2015a; Le et al. 2015b; Tokonami et al. 2013; Tokonami et al. 2012). Major limiting factors in CIP technology are their low affinity and the difficulties associated with the complete removal of the template (Lopez-Roldan et al. 2013; Velusamy et al. 2010).

In the work reported herein, we explored the use of a functional monomer, 3aminophenylboronic acid (3-APBA), for the electrochemical fabrication of CIPs with improved affinity and ease of template removal. These improvements were made possible by the presence of the boronic acid group in the polymeric matrix.

Boronic acid is well known to interact, at physiological pHs or above, with 1,2- or 1,3-diols. This interaction has already been demonstrated for the detection of diol-containing molecules such as sugars, dopamine and bacteria (Badhulika and Mulchandani 2015; Badhulika et al. 2014; Deore and Freund 2003). 
Electrochemically fabricated poly(3-aminophenylboronic acid) (PAPBA) based MIPs have been already reported for the detection of saccharides and proteins (Deore and Freund 2003; Rick and Chou 2006). The presence of boronic acid groups at the interface between the CIPs and solution is expected to improve, as already shown in the case of planar polymeric surfaces (Polsky et al. 2008; Xue et al. 2010), the affinity of the polymer towards bacterial cells due to presence on the outer wall of the bacteria of a variety of diol-rich biomolecules such as teichoic acid, peptidoglycan and lipopolysaccharides. Furthermore, the reversibility of the diol-boronic acid group interaction has been demonstrated to allow the selective capture and release of biomolecules and cells (Aytaç et al. 2011; Ivanov et al. 2006; Ren et al. 2009; Xue et al. 2010; Zhong et al. 2015a; Zhong et al. 2015b).

In this work, we demonstrated that the use of 3-APBA for the electrochemical fabrication of CIPs resulted in a synergistic interaction between the steric recognition of the cavities and the chemical affinity of boronic acid for diols. Furthermore, the reversibility of the boronic acid-diol interaction facilitated the release of the cell templates. Finally the use of 3-APBA-based CIP for the label-free detection of S. epidermidis, via electrochemical impedance spectroscopy (EIS), was demonstrated.

\section{Materials and methods}

\subsection{Materials and Apparatus}

Bacterial strains were either obtained from the Culture Collection of the University of Gothenburg, Sweden (Escherichia coli and Deinococcus proteolyticus) or donated by the 
Linköping University Hospital (Staphylococcus epidermidis and Streptococcus pneumoniae). Brain heart infusion broth Sigma-Aldrich) were used to culture bacteria. Pyrrole monomer (Sigma-Aldrich, St. Louis, USA) was distilled and stored at $-20^{\circ} \mathrm{C}$ prior to use. Potassium ferricyanide $\left(\mathrm{K}_{3}\left[\mathrm{Fe}(\mathrm{CN})_{6}\right]\right)$ and potassium ferrocyanide $\left(\mathrm{K}_{4}\left[\mathrm{Fe}(\mathrm{CN})_{6}\right]\right)$ were obtained from $\mathrm{E}$. Merck (Germany) and 3-aminophenylboronic acid (3-APBA) monomer, o-phenylenediamine (oPD, $\geq 98 \%$ ), ready to use phosphate buffer saline buffer tablets (PBS, 10x, $\mathrm{pH} 7.4$ ), sodium fluoride (NaF), concentrated sulfuric acid $\left(\mathrm{H}_{2} \mathrm{SO}_{4}\right)$, Tris- $\mathrm{HCl}$, sodium dihydrogen phosphate $\left(\mathrm{NaH}_{2} \mathrm{PO}_{4}\right)$, concentrated hydrochloric acid $(\mathrm{HCl})$, and fructose were purchased from SigmaAldrich (Sweden). All solutions were prepared in high purity water (18 M $\Omega$ ) obtained using a Milli-Q RG system (Stockholm, Sweden).

Fabrication of CIPs was performed either on in-house fabricated $\mathrm{Au}$ substrates or on commercially available Au disk electrodes (GDE) (internal diameter $2 \mathrm{~mm}$ from CHI Instruments, USA). In-house substrates were fabricated by evaporating $2000 \AA$ of Au and $100 \AA$ of $\mathrm{Ti}$ (adhesion layer) onto a Si wafer, which was subsequently cut into $2 \mathrm{x} 1 \mathrm{~cm}^{2}$ electrodes. Electrochemical deposition of the polymeric films and impedimetric measurements were carried out using either an EmStat2 electrochemical workstation together with PSTrace software (Palm Sense, The Netherlands) or an IviumStat.XR electrochemical analyser coupled with dedicated software (Ivium, Eindhoven, Netherlands). An Ag/AgCl, 3 M NaCl (CHI Instruments, USA) and a Pt mesh were used as reference and counter electrodes, respectively, during the electrochemical synthesis and characterisation of the MIPs.

\subsection{Bacterial cultivation}


Bacterial strains were cultured in Brain heart infusion broth at $37^{\circ} \mathrm{C}$ and $170 \mathrm{rpm}$ overnight $(\approx 18$ h). The cultured bacterial cells were collected by centrifugation (4000 g, 5 min) and the pellet was re-suspended in sterilised PBS. The washing process was repeated three times completely to remove impurities. The final bacterial cell concentration was adjusted by dilution guided by optical density measurement of solutions at $600 \mathrm{~nm}$ using a spectrophotometer (Shimadzu UV1601 PC, Japan).

\subsection{CIP and NIP fabrication}

Prior to use, the GDE surface was polished on a cloth pad with wet alumina slurry (1, 0.3 and $0.05 \mu \mathrm{m}$, CHI Instruments, USA) to a mirror finish, washed with deionised water and subjected to cyclic potential sweeps $(0.2-1.5 \mathrm{~V})$ in $0.5 \mathrm{M} \mathrm{H}_{2} \mathrm{SO}_{4}$ until obtaining a stable cyclic voltammogram. The CIP was electrochemically synthesised at a constant potential (+ $950 \mathrm{mV}$ vs $\mathrm{Ag} / \mathrm{AgCl}, 3 \mathrm{M} \mathrm{NaCl}$ ); the polymerisation was terminated when a predetermined amount of charge (3.2 mC) had passed thus allowing good control of the film thickness. CIPs were fabricated from $50 \mathrm{mM}$ 3-APBA and $50 \mathrm{mM}$ NaF (Deore and Freund 2003; Badhulika and Mulchandani 2015) in 10x PBS (pH 7.4) in the presence (cell-imprinted, CIP) and in the absence (non-imprinted polymers, NIP) of S. epidermidis ( $10^{9} \mathrm{cfu} / \mathrm{mL}$ final concentration). The fabricated CIPs were then treated for $30 \mathrm{~min}$ with fructose $(20 \mathrm{mM})$, for competitive detachment of the cells from the surface (Polsky et al. 2008), followed by washing with plenty of running deionised water to remove the bacterial cells from the polymer network. Finally, prior to storage, the electrodes were immersed in phosphate solution $(\mathrm{pH}$ 2.2) for 20 min to remove bound fructose and to 
reactivate the boronic groups of the polymer (Springsteen and Wang 2002). The activated electrodes were stored in Tris-HCl (0.1 M, pH 8.5) until further use (Polsky et al. 2008).

\subsection{Bacteria detection test}

The ability of the CIPs to detect the target bacteria, S. epidermidis, was evaluated by incubation, in quiescent conditions, of the modified CIP electrode in 10x PBS (pH 7.4) containing defined concentrations of bacterial cells for $30 \mathrm{~min}$. Electrochemical impedance spectroscopy was carried out in the presence of $5 \mathrm{mM} \mathrm{K} \mathrm{K}_{3}\left[\mathrm{Fe}(\mathrm{CN})_{6}\right] / \mathrm{K}_{4}\left[\mathrm{Fe}(\mathrm{CN})_{6}\right](1: 1)$ in PBS. Impedance measurements were in the frequency range of $0.1-100,000 \mathrm{~Hz}$ at a bias potential of $0.0 \mathrm{mV}$ vs. OCP potential. The amplitude of the applied sine wave potential was $5 \mathrm{mV}$. The Nyquist plots obtained were fitted to an equivalent circuit to extract the value of the charge transfer resistance $\left(\mathrm{R}_{\mathrm{ct}}\right)$.

\subsection{Scanning electron and fluorescent microscopies}

The Scanning Electron Microscopy (SEM) images were taken using a Leo 1550 Gemini SEM operating at $8.0 \mathrm{keV}$ for polymer characterisation purpose. For evaluating selectivity of CIP, we performed fluorescent microscopy observations (ZEISS, Germany). CIPs separately prepared on Au planar electrodes $\left(1 \mathrm{~cm}^{2}\right)$ were used for these microscopy studies. All cell samples were visualised by staining with ethidium bromide (0.05\%) for $45 \mathrm{~min}$.

\section{Results and discussions}

\subsection{Electrochemical whole-cell imprinting}

CIPs based on PPy (Tokonami et al. 2013) and poly(o-phenylenediamine (Po-PD) polymer were successfully fabricated (Fig. S1-Supporting Information) following the previously described 
methods detailed in brief in the supporting information (Figure S1). In order to allow the further use of the CIPs removal of the template is required, but this step is not simple in the case of large biomolecules and whole cells. Mild conventional approaches, such as washing and soaking in water (Cheng et al. 2001), sonication, mild acidic and alkaline treatment (Ameli and Alizadeh 2012; Gómez-Caballero et al. 2008), which have been successfully applied to the removal of small templates are not effective in the case of whole cells (Levi and Srebnik 2010). On the other hand, applying harsh conditions to remove the template damage the polymer and created cavities (Lorenzo et al. 2011). In the case of casting methods (Iskierko et al. 2016), due to the feeble interactions between the cell and the polymer, templates can be removed by physical treatments like sonication or soaking and washing with water (Ren et al. 2013; Schirhagl et al. 2012a). Unfortunately, in the case of electrochemically fabricated CIPs, the use of such moderate conditions were insufficient to detach bacterial cells from the polymer network (Fig. S2Supporting Information). Attempts to remove bacterial cells, following an approach inspired by the work of Tokonamy et al. [28] (treatment of the CIPs with lysozyme $(10 \mathrm{mg} / \mathrm{mL})$ at $4^{\circ} \mathrm{C}$ for 2 $\mathrm{h}$ followed by washing in $10 \%$ Triton for $80 \mathrm{~min}$, and constant potential treatment (+ $980 \mathrm{mV})$ in 0.1 $\mathrm{M} \mathrm{NaOH}$ solution) was not successful. As can clearly be seen from Fig. S2 significant damages in the cavities and/or the partial retention of the bacterial cell wall were observed. In order to overcome this significant problem, CIPs using 3-APBA as functional monomer were fabricated (Gao et al. 2013; Li et al. 2013).

Figure 1 is a schematic of the rationale behind the use of 3-APBA for the fabrication of CIPs. When pre-mixed with the template cell, the phenylboronic acid groups are expected to attach to the cis-diols present on the bacterial surface (a). The subsequent electrochemical polymerisation captures the bacterial cells in the polymeric network (b); monomers previously present on the 
bacterial surface are expected to be integrated in the polymer network adding, in this way, to create the structural and chemical affinity. By removing bacterial cells from the polymer, complementary cavities remain at the polymer surface, which not only present structural (shape and size) specificity, but also chemical specificity via the diol molecules found on the surface of the cell walls of the template (S. epidermidis).

\section{Location of Figure 1}

Electrochemical fabrication of PAPBA based CIPs and the removal of cells from the polymer network, by competitive displacement with fructose and washing with deionised water, were successfully achieved. Typical chronoamperometric, curves recorded during the fabrication of the CIPs and the NIPs, and a schematic description of the polymerisation process, are reported in Fig. S3. Both the deposition processes were consistent with the deposition profile reported for the chronoamperometric electrodeposition of aniline (Yano et al. 1997). In the ortho-position to an amino-group, the boronic acid group does not hamper the polyaniline growth (Nikitina et al. 2015). At the beginning of the process, both the amperograms presented a decrease in current, which was probably associated with a slow seeding processes taking place at the electrode surface. This initial step is then followed by a region characterised by fast current ramping associated with first a nucleation step followed by a bulk deposition of the film. Comparing the amperograms obtained with those reported in the literature for aniline (Yano et al. 1997), the presence of the boronic acid substitution and of the less conductive material, i.e. bacteria, 
significantly slowed the seeding step. This is due to the fact that the presence of an electron attracting group significantly reduced the reactivity of the aniline making the polymerisation process slower. Fig.2a shows the SEM images of bacterial cells captured in the PAPBA polymer network after electrochemical polymerisation. The shape of the complementary cavities on the polymer surfaces after removal of the bacteria cells are clearly seen in Fig.2b. It should be noted that the potential used during the electrochemical fabrication of the polymer is crucial for the success of this process. If the potential is too low $(<+900 \mathrm{mV})$ a poor film is deposited, while too high potential $(>+980 \mathrm{mV})$ results in films with stronger interconnection with the template that could not be completely removed from the CIP. On the other hand, the use of $+950 \mathrm{mV}$ resulted in the fabrication of highly reproducible films from which the easy and quantitative removal of the bacterial cells was possible.

These significant differences can probably be ascribed to the fact that a higher potential gives a faster polymerisation which results in the formation of rougher polymers (G.B. Street 1983; Golabi et al. 2016; Xu et al. 2005) and more branched polymers that could result in a high surface area providing a good adhesion of the bacterial cells and subsequent irreversible entrapment of them. Consequently, there is a limited potential window that allows the fabrication of CIPs with the desired properties.

\section{Location of Figure 2}


The effect of polymer thickness was also evaluated to optimise the synthesis and efficient bacterial removal processes. Fig.3 shows three CIPs with different polymer thickness; these were obtained by stopping the electrochemical polymerisation process after different charges had been passed. Fig. 3a shows a thin CIP $(\leq 20 \mathrm{~nm})$ in which the complementary cavities have insufficient specificity for the target cell, S. epidermidis. In Fig.3b, the CIP thickness is appropriate $(\leq 100 \mathrm{~nm})$ for both specific capture and release of the target cells. Figure 3c shows a thick CIP ( $\geq 250 \mathrm{~nm}$ ) in which $S$. epidermidis is stuck in the thick polymer layer making the release process difficult. To release the bacterial cells from the optimised CIP network, the film was incubated with fructose (20 mM solution), which is known to have a strong affinity for boronic acid groups (Ma and Yang 2005; Polsky et al. 2008; Torun et al. 2009). The treatment with fructose solution, followed by washing with deionised water resulted in the quantitative removal of the bacterial cells from the CIP (Fig. 2b). The bound fructose molecules were then removed by further treatment at low $\mathrm{pH}$ to reactivate the boronic groups present in the CIPs.

\section{Location of Figure 3}

\subsection{Electrochemical evaluation of cell-imprinted polymer}

EIS was used to characterise the fabricated polymers and the removal step from CIP. Fig. 4 shows the EIS of bare Au electrode, NIP and CIP before and after removal of the bacterial cells (modified CIP). The presence of the NIP (blue line) and of the CIP (red line) resulted in a significant increase in the high frequency semicircle, when compared to the bare GDE. This 
result confirmed the successful formation of the polymer layer onto the GDE. Notably a much higher resistance was recorded in the case of the CIPs; this result is consistent with the presence of bacterial cells in the polymer network, which have a significant electrostatic repulsion effect on the redox probe used in the measurement due to their negative surface charge. A significant change was observed in the impedance of the CIP after the treatment process for the removal of the bacterial cells; this significant loss in charge transfer resistance was ascribed to (i) the loss of electrostatic repulsion and (ii) to the high porosity of the polymer film after cell removal.

After bacterial removal and regeneration of the boronic acid groups, the regenerated CIP electrodes were incubated with different concentrations $\left(10^{1}\right.$ to $\left.10^{8} \mathrm{cfu} / \mathrm{mL}\right)$ of target bacteria, $S$. epidermidis. Fig. 5A shows the EIS response of the CIP incubated in solutions with different bacterial concentrations. The capture of bacteria cells in the CIP network partially blocks the electron transfer between the redox probe and the electrode surface with a subsequent increase of the overall charge transfer resistance of the film beside the repulsive interactions with probe molecules as mentioned before. Fig.5B shows the linear relationship of the bacterial concentration and the EIS response of the electrode. The optimum incubation time was 30 minutes, where the highest differences in the responses of NIP and CIP were detected (Figure S4, Supporting Information).

In order to minimise the variability between different CIP sensors, the relative variation of $\mathrm{R}_{\mathrm{ct}}$, $[\Delta \mathrm{R} / \mathrm{R}(\Omega)]$ was used as analytical response (Nasef et al. 2010). This value was calculated as follows:
$\Delta \mathrm{R} / \mathrm{R}(\Omega)=\left(\mathrm{R}_{\mathrm{cta}}-\mathrm{R}_{\mathrm{ct}} \Omega\right) / \mathrm{R}_{\mathrm{ct}} \Omega$
(eq. 1) 
Where $R_{c t a}$ is the value of $R_{c t}$ after incubation with the concentration of target bacteria and $R_{c t} \Omega$ is the value recorded for the CIP prior to incubation with bacteria.

The binding isotherm of the MIP-modified electrode was fitted using a model for two types of simultaneous binding; at the sites of specific recognition inside the polymer film and on the surface of the electrode due to non-specific adsorption (Karimian et al. 2013):

$$
\frac{\mathrm{R}-\mathrm{R}_{0}}{\mathrm{R}_{0}}=\frac{\mathrm{B}_{\mathrm{MAX}} \mathrm{C}}{\mathrm{K}_{\mathrm{D}}+\mathrm{C}}+\mathrm{N}_{\mathrm{S}} \mathrm{C}
$$

Where: $\mathrm{C}$ is the bulk concentration of the target, $\mathrm{B}_{\mathrm{MAX}}$ is the maximum number of binding sites in the MIP; $\mathrm{K}_{\mathrm{D}}$ is the equilibrium dissociation constant; and $\mathrm{N}_{\mathrm{S}}$ is the binding constant for nonspecific adsorption. The value of $\mathrm{K}_{\mathrm{D}}$ obtained by fitting is $1.28 \times 10-8 \mathrm{M}(\mathrm{R} 20.94) \mathrm{cfu} / \mathrm{mL}$.

\section{Location of Figure 4}

\section{Location of Figure 5}

\subsection{Selectivity studies}

The affinity of the CIPs was evaluated by comparing their EIS responses to different concentrations of S. epidermidis with those recorded in the case of NIP. Fig.6a shows the normalised EIS responses of the CIP and NIP for S. epidermidis.

As it can be seen from Fig. 6a, the response obtained for CIP was significantly higher than those for NIP at the lower target concentrations, confirming the improved affinity due to the presence 
of the cavities. Nevertheless, the difference in response was progressively reduced with increasing bacteria concentration in the solution. This result is consistent with the presence of boronic groups on the both the CIP and NIP surfaces. The presence of the boronic acid groups in electrochemically fabricated PAPBA films have been already shown to increase cell adhesion onto the surface (Wannapob et al. 2010; Xue et al. 2010) and also found application in bacterial detection (Wannapob et al. 2010).

In order to confirm this, fluorescence imaging experiments were performed with CIP, NIP and polyaniline (NIP-PA) that had a similar polymer backbone, but that did not have the boronic acid groups. As shown in Fig. 6b, when the three surfaces were put in contact with $10^{6} \mathrm{cfu} / \mathrm{mL}$ of $S$. epidermidis adsorption and capture of the bacteria were recorded. Although the expected high non-specific adhesion at the NIP surface was observed, the CIP still showed higher affinity for the target bacteria.

\section{Location of Figure 6}

The selectivity of CIPs was also investigated by comparing the capture of S. epidermidis with those recorded for non-target bacterial strains, D. proteolyticus, E. coli and S. pneumoniae. Fig. 7 shows the different normalised EIS responses of the CIPs for the target and non-target bacteria at

a concentration of $10^{4} \mathrm{cfu} / \mathrm{mL}$. The results of this experiment clearly demonstrate the ability of CIPs to discriminate the target from similar bacteria, in terms of shape and size, such as $S$. 
pneumoniae and $D$. proteolyticus. Table S1 shows the imprinting factor and selectivity factor for the imprinted polymer (Uzun et al. 2009).

\section{Location of Figure 7}

\section{Conclusions}

We demonstrated the use of 3-APBA as a functional monomer for the electrochemical fabrication of CIP with high affinity for bacteria. The proposed CIP, when fabricated under optimal conditions (potential and total charge), presented two significant advantages: (i) a high affinity, due to the combination of morphological and chemical recognition of the target; and (ii) easy removal of template, by the use of a competitive process, without significant damage to the polymer structure. CIPs specific for $S$. epidermidis were fabricated on GDE, via constant potential methods, and used for the label-free detection, via EIS, of the target bacteria. The CIP

sensor was shown to respond linearly to S. epidermidis concentrations in the range $10^{3}$ to $10^{7}$ $\mathrm{cfu} / \mathrm{mL}$. Furthermore, the CIP-based sensor delivered, at least at low concentrations, a significantly higher response than the corresponding NIP, confirming the importance of the cavities in the recognition process. In addition, the CIP sensor was shown to be highly specific for S. epidermidis when compared to other non-target bacteria such as D. proteolyticus, E. coli and S. pneumoniae.

On the one hand, the presence of boronic acid groups resulted in significant benefit by improving the template removal and increasing the specific interaction within the imprinted cavities. However, the presence of boronic acid groups on the surface of the polymer as well as in the 
imprinted cavities, tended to increase non-specific absorption, as evidenced by the results with NIPs. Further work will include strategies to deactivate this undesirable side effect. Despite this shortcoming, the introduction of a functional derivatives in addition to established cell imprinting, led to substantial improvement in the performance of the CIP and a promising strategy of for cell capture, sensing and release. We envisage this as a viable approach for inexpensive, simple and rapid detection of pathogens in food and possibly environmental samples.

\section{Acknowledgements}

Mohsen Golabi would like to thank the Ministry of Science Research and Technology of Iran (www.msrt.ir) for supporting his Ph.D. Anthony Turner, Valerio Beni and Edwin Jager would like to thank Linköping University for the financial support; Edwin Jager would also thank the Swedish Research Council contract nr VR-2014-3079 for financial support of the project. The authors would like to especially thank Dr. Lokman Uzun for his very valuable contribution to this paper.

\section{References:}

Aherne, A., Alexander, C., Payne, M.J., Perez, N., Vulfson, E.N., 1996. Bacteria-mediated lithography of polymer surfaces. J. Am. Chem. Soc. 118(36), 8771-8772.

Allos, B.M., Moore, M.R., Griffin, P.M., Tauxe, R.V., 2004. Surveillance for sporadic foodborne disease in the 21st century: The FoodNet perspective. Clin. Infect. Dis. 38(SUPPL. 3), S115-S120.

Ameli, A., Alizadeh, N., 2012. Nanostructured conducting molecularly imprinted polymer for selective uptake/release of naproxen by the electrochemically controlled sorbent. Anal. Biochem. 428(2), 99-106. Aytaç, S., Kuralay, F., Boyacı, i.H., Unaleroglu, C., 2011. A novel polypyrrole-phenylboronic acid based electrochemical saccharide sensor. Sensors and Actuators B: Chemical 160(1), 405-411.

Badhulika, S., Mulchandani, A., 2015. Molecular imprinted polymer functionalized carbon nanotube sensors for detection of saccharides. Applied Physics Letters 107(9). 
Badhulika, S., Tlili, C., Mulchandani, A., 2014. Poly(3-aminophenylboronic acid)-functionalized carbon nanotubes-based chemiresistive sensors for detection of sugars. Analyst 139(12), 3077-3082.

Bagheryan, Z., Raoof, J.B., Golabi, M., Turner, A.P.F., Beni, V., 2016. Diazonium-based impedimetric aptasensor for the rapid label-free detection of Salmonella typhimurium in food sample. Biosens. Bioelectron. 80, 566-573.

Call, D.R., Borucki, M.K., Loge, F.J., 2003. Detection of bacterial pathogens in environmental samples using DNA microarrays. Journal of Microbiological Methods 53(2), 235-243.

Cheng, Z., Wang, E., Yang, X., 2001. Capacitive detection of glucose using molecularly imprinted polymers. Biosens. Bioelectron. 16(3), 179-185.

Cohen, T., Starosvetsky, J., Cheruti, U., Armon, R., 2010. Whole cell imprinting in sol-gel thin films for bacterial recognition in liquids: Macromolecular fingerprinting. International Journal of Molecular Sciences 11(4), 1236-1252.

Deore, B., Freund, M.S., 2003. Saccharide imprinting of poly(aniline boronic acid) in the presence of fluoride. Analyst 128(6), 803-806.

Dickert, F.L., Hayden, O., 2002. Bioimprinting of polymers and sol-gel phases. Selective detection of yeasts with imprinted polymers. anal. chem 74(6), 1302-1306.

Dover, J.E., Hwang, G.M., Mullen, E.H., Prorok, B.C., Suh, S.-J., 2009. Recent advances in peptide probebased biosensors for detection of infectious agents. Journal of Microbiological Methods 78(1), 10-19. G.B. Street, T.C.C., R.H. Geiss, V.Y. Lee, A. Nazzal, P. Pfluger and J.C. Scott, 1983. Characterization of polypyrrole. Journal de Physique 44(C3), 599-606.

Gao, F.X., Ma, X.T., He, X.W., Li, W.Y., Zhang, Y.K., 2013. Smart surface imprinting polymer nanospheres for selective recognition and separation of glycoprotein. Colloids Surf. Physicochem. Eng. Aspects 433, 191-199.

Golabi, M., Turner, A.P.F., Jager, E.W.H., 2016. Tuning the Surface Properties of Polypyrrole Films for Modulating Bacterial Adhesion. Macromol. Chem. Phys.

Gómez-Caballero, A., Unceta, N., Aranzazu Goicolea, M., Barrio, R.J., 2008. Evaluation of the selective detection of 4,6-dinitro-o-cresol by a molecularly imprinted polymer based microsensor electrosynthesized in a semiorganic media. Sensors and Actuators B: Chemical 130(2), 713-722. Iskierko, Z., Sharma, P.S., Bartold, K., Pietrzyk-Le, A., Noworyta, K., Kutner, W., 2016. Molecularly imprinted polymers for separating and sensing of macromolecular compounds and microorganisms. Biotechnology Advances 34(1), 30-46.

Ivanov, A.E., Panahi, H.A., Kuzimenkova, M.V., Nilsson, L., Bergenståhl, B., Waqif, H.S., Jahanshahi, M., Galaev, I.Y., Mattiasson, B., 2006. Affinity adhesion of carbohydrate particles and yeast cells to boronatecontaining polymer brushes grafted onto siliceous supports. Chemistry - A European Journal 12(27), 7204-7214.

Karimian, N., Vagin, M., Zavar, M.H.A., Chamsaz, M., Turner, A.P.F., Tiwari, A., 2013. An ultrasensitive molecularly-imprinted human cardiac troponin sensor. Biosensors and Bioelectronics 50, 492-498.

Kemp, M., Jensen, K.H., Dargis, R., Christensen, J.J., 2010. Routine ribosomal PCR and DNA sequencing for detection and identification of bacteria. Future Microbiology 5(7), 1101-1107.

Le, D.Q., Takai, M., Suekuni, S., Tokonami, S., Nishino, T., Shiigi, H., Nagaoka, T., 2015a. Development of an Observation Platform for Bacterial Activity Using Polypyrrole Films Doped with Bacteria. anal. chem 87(7), 4047-4052.

Le, D.Q., Tokonami, S., Nishino, T., Shiigi, H., Nagaoka, T., 2015b. Electrochemical evaluation of poly(3,4ethylenedioxythiophene) films doped with bacteria based on viability analysis. Bioelectrochemistry 105, 50-55. 
Lee, M.-H., Thomas, J.L., Chen, W.-J., Li, M.-H., Shih, C.-P., Lin, H.-Y., 2015a. Fabrication of Bacteriaimprinted Polymer Coated Electrodes for Microbial Fuel Cells. ACS Sustainable Chemistry \& Engineering 3(6), 1190-1196.

Lee, M.H., Thomas, J.L., Chen, W.J., Li, M.H., Shih, C.P., Lin, H.Y., 2015b. Fabrication of bacteriaimprinted polymer coated electrodes for microbial fuel cells. ACS Sustainable Chemistry and Engineering 3(6), 1190-1196.

Lee, M.H., Thomas, J.L., Li, M.H., Shih, C.P., Jan, J.S., Lin, H.Y., 2015c. Recognition of Rhodobacter sphaeroides by microcontact-imprinted poly(ethylene-co-vinyl alcohol). Colloids and Surfaces B: Biointerfaces 135, 394-399.

Levi, L., Srebnik, S., 2010. Simulation of Protein-Imprinted Polymers. 1. Imprinted Pore Properties. The Journal of Physical Chemistry B 114(1), 107-114.

Li, L., Lu, Y., Bie, Z., Chen, H.Y., Liu, Z., 2013. Photolithographic boronate affinity molecular imprinting: A general and facile approach for glycoprotein imprinting. Angewandte Chemie - International Edition 52(29), 7451-7454.

Lopez-Roldan, R., Tusell, P., Cortina, J.L., Courtois, S., Cortina, J.L., 2013. On-line bacteriological detection in water. TrAC, Trends Anal. Chem. 44, 46-57.

Lorenzo, R.A., Carro, A.M., Alvarez-Lorenzo, C., Concheiro, A., 2011. To remove or not to remove? The challenge of extracting the template to make the cavities available in molecularly imprinted polymers (MIPs). International Journal of Molecular Sciences 12(7), 4327-4347.

Ma, Y., Yang, X., 2005. One saccharide sensor based on the complex of the boronic acid and the monosaccharide using electrochemical impedance spectroscopy. Journal of Electroanalytical Chemistry 580(2), 348-352.

Namvar, A., Warriner, K., 2007. Microbial imprinted polypyrrole/poly(3-methylthiophene) composite films for the detection of Bacillus endospores. Biosens. Bioelectron. 22(9-10), 2018-2024.

Nasef, H., Beni, V., O'Sullivan, C.K., 2010. Labelless electrochemical melting curve analysis for rapid mutation detection. Analytical Methods 2(10), 1461-1466.

Nikitina, V.N., Kochetkov, I.R., Karyakina, E.E., Yatsimirsky, A.K., Karyakin, A.A., 2015. Tuning electropolymerization of boronate-substituted anilines: Fluoride-free synthesis of the advanced affinity transducer. Electrochemistry Communications 51, 121-124.

Özalp, V.C., Bilecen, K., Kavruk, M., Avni Öktem, H., 2013. Antimicrobial aptamers for detection and inhibition of microbial pathogen growth. Future Microbiology 8(3), 387-401.

Polsky, R., Harper, J.C., Wheeler, D.R., Arango, D.C., Brozik, S.M., 2008. Electrically addressable cell immobilization using phenylboronic acid diazonium salts. Angewandte Chemie - International Edition 47(14), 2631-2634.

Qi, P., Wan, Y., Zhang, D., 2013. Impedimetric biosensor based on cell-mediated bioimprinted films for bacterial detection. Biosensors and Bioelectronics 39(1), 282-288.

Ren, K., Banaei, N., Zare, R.N., 2013. Sorting Inactivated Cells Using Cell-Imprinted Polymer Thin Films. ACS Nano 7(7), 6031-6036.

Ren, K., Zare, R.N., 2012. Chemical Recognition in Cell-Imprinted Polymers. ACS Nano 6(5), 4314-4318.

Ren, L., Liu, Z., Liu, Y., Dou, P., Chen, H.Y., 2009. Ring-opening polymerization with synergistic comonomers: Access to a boronate-functionalized polymeric monolith for the specific capture of c/s-diolcontaining biomolecules under neutral conditions. Angewandte Chemie - International Edition 48(36), 6704-6707.

Rick, J., Chou, T.-C., 2006. Using protein templates to direct the formation of thin-film polymer surfaces. Biosensors and Bioelectronics 22(4), 544-549.

Schirhagl, R., 2014. Bioapplications for molecularly imprinted polymers. anal. chem 86(1), 250-261. 
Schirhagl, R., Hall, E.W., Fuereder, I., Zare, R.N., 2012a. Separation of bacteria with imprinted polymeric films. Analyst 137(6), 1495-1499.

Schirhagl, R., Ren, K., Zare, R.N., 2012b. Surface-imprinted polymers in microfluidic devices. Science China Chemistry 55(4), 469-483.

Sharma, P.S., Pietrzyk-Le, A., D'Souza, F., Kutner, W., 2012. Electrochemically synthesized polymers in molecular imprinting for chemical sensing. Analytical and Bioanalytical Chemistry 402(10), 3177-3204. Sheikhzadeh, E., Chamsaz, M., Turner, A.P.F., Jager, E.W.H., Beni, V., 2016. Label-free impedimetric biosensor for Salmonella Typhimurium detection based on poly [pyrrole-co-3-carboxyl-pyrrole] copolymer supported aptamer. Biosens. Bioelectron. 80, 194-200.

Skottrup, P.D., Nicolaisen, M., Justesen, A.F., 2008. Towards on-site pathogen detection using antibodybased sensors. Biosens. Bioelectron. 24(3), 339-348.

Springsteen, G., Wang, B., 2002. A detailed examination of boronic acid-diol complexation. Tetrahedron 58(26), 5291-5300.

Tokonami, S., Nakadoi, Y., Takahashi, M., Ikemizu, M., Kadoma, T., Saimatsu, K., Dung, L.Q., Shiigi, H., Nagaoka, T., 2013. Label-free and selective bacteria detection using a film with transferred bacterial configuration. anal. chem 85(10), 4925-4929.

Tokonami, S., Saimatsu, K., Nakadoi, Y., Furuta, M., Shiigi, H., Nagaoka, T., 2012. Vertical immobilization of viable bacilliform bacteria into polypyrrole films. Anal. Sci. 28(4), 319-322.

Torun, Ö., Dudak, F.C., Baş, D., Tamer, U., Boyacı, I.H., 2009. Thermodynamic analysis of the interaction between 3-aminophenylboronic acid and monosaccharides for development of biosensor. Sensors and Actuators B: Chemical 140(2), 597-602.

Uzun, L., Say, R., Ünal, S., Denizli, A., 2009. Production of surface plasmon resonance based assay kit for hepatitis diagnosis. Biosensors and Bioelectronics 24(9), 2878-2884.

Uzun, L., Turner, A.P.F., 2016. Molecularly-imprinted polymer sensors: Realising their potential. Biosens. Bioelectron. 76, 131-144.

Velusamy, V., Arshak, K., Korostynska, O., Oliwa, K., Adley, C., 2010. An overview of foodborne pathogen detection: In the perspective of biosensors. Biotechnology Advances 28(2), 232-254.

Wannapob, R., Kanatharana, P., Limbut, W., Numnuam, A., Asawatreratanakul, P., Thammakhet, C., Thavarungkul, P., 2010. Affinity sensor using 3-aminophenylboronic acid for bacteria detection. Biosens. Bioelectron. 26(2), 357-364.

Whitcombe, M.J., Kirsch, N., Nicholls, I.A., 2014. Molecular imprinting science and technology: A survey of the literature for the years 2004-2011. Journal of Molecular Recognition 27(6), 297-401.

Xu, L.B., Chen, W., Mulchandani, A., Yan, Y.S., 2005. Reversible conversion of conducting polymer films from superhydrophobic to superhydrophilic. Angewandte Chemie-International Edition 44(37), 60096012.

Xue, Z., Bai, H.J., Xu, J.J., Chen, H.Y., Zhu, Y.H., 2010. A reusable interface constructed by 3aminophenylboronic acid functionalized multiwalled carbon nanotubes for cell capture, release, and cytosensing. Advanced Functional Materials 20(6), 992-999.

Yano, J., Yoshikawa, K.I., Kitani, A., 1997. Kinetic Study of the Electropolymerization of Aniline Using Chronoamperometric Techniques. Analytical Sciences 13(5), 741-746.

Yilmaz, E., Majidi, D., Ozgur, E., Denizli, A., 2015. Whole cell imprinting based Escherichia coli sensors: A study for SPR and QCM. Sensors and Actuators, B: Chemical 209, 714-721.

Yoo, S.M., Lee, S.Y., 2016. Optical Biosensors for the Detection of Pathogenic Microorganisms. Trends Biotechnol. 34(1), 7-25.

Zhong, M., Dai, Y., Fan, L., Lu, X., Kan, X., 2015a. A novel substitution -sensing for hydroquinone and catechol based on a poly(3-aminophenylboronic acid)/MWCNTs modified electrode. Analyst 140(17), 6047-6053. 
Zhong, M., Teng, Y., Pang, S., Yan, L., Kan, X., 2015b. Pyrrole-phenylboronic acid: A novel monomer for dopamine recognition and detection based on imprinted electrochemical sensor. Biosens. Bioelectron. 64(0), 212-218.

Zhou, J., 2003. Microarrays for bacterial detection and microbial community analysis. Curr. Opin. Microbiol. 6(3), 288-294.

\section{Scheme and Figure Captions}

Figure 1. Schematic representation of whole cell imprinting. Boronic acid groups attach to the surface of bacteria (a). Electropolymerisation preserves the structure of the cell at the polymer network (b). Bacterial cells are removed and the complementary cavities remain (c). Cavities containing boronic acid groups increase affinity of the preserved complementary shape of target bacteria (d).

Figure 2. SEM images of cell-imprinted polymer. (a) S. epidermidis captured in PAPBA imprinted polymer, and (b) the remaining shape-complementary cavities after removing bacterial cells.

Figure 3. SEM images of cell-imprinted polymer. S. epidermidis captured in PAPBA with different thicknesses, $(A \leq 20 \mathrm{~nm}, \mathrm{~B} \leq 100 \mathrm{~nm}$, and $\mathrm{C} \geq 250 \mathrm{~nm})$. Polymers were fabricated at constant a potential of $+950 \mathrm{mV}$. The CIP solution contained $50 \mathrm{mM}$ 3-APBA in 10x PBS containing S. epidermidis $\left(10^{9} \mathrm{cfu} / \mathrm{mL}\right)$ and $50 \mathrm{mM} \mathrm{NaF}$. 
Figure 4. Electrochemical impedance spectra at bare GDE, CIP, NIP and modified CIP. Experimental details: 5 mM K3[Fe(CN)6]/K4[Fe(CN)6] (1:1) in PBS. Impedance measurements were in the frequency range $0.1-100,000 \mathrm{~Hz}$ at a bias potential of $0.0 \mathrm{mV}$ vs. OCP potential. The amplitude of the applied sine wave potential was $5 \mathrm{mV}$.

Figure 5. EIS results for cell-imprinted polymer incubated with different concentrations of $S$. epidermidis (a) and the calibration curve of $\Delta \mathrm{Rct} / \mathrm{Rct}$ versus log concentration of $S$. epidermidis. The data are averages of at least three independent experiments and error bars indicate standard deviations (b). Experimental details: 5 mM K3[Fe(CN)6]/K4[Fe(CN)6] (1:1) in PBS. Impedance measurements were in the frequency range $0.1-100,000 \mathrm{~Hz}$ at a bias potential of $0.0 \mathrm{mV}$ vs. OCP potential. The amplitude of the applied sine wave potential was $5 \mathrm{mV}$.

Figure 6. Affinity of CIP for its target, S. epidermidis. A) Normalised EIS response of CIP and APBA-NIP to S. epidermidis. B) Fluorescent images of S. epidermidis adhered to NIP made by Polyaniline (PA-NIP), PAPBA-NIP and PAPBA-CIP. The data are averages of at least three independent experiments and error bars indicate standard deviations.

Figure 7. Specificity of the PAPBA-CIP for its target S.epidermidis vs D. proteolyticus, E. coli and $S$. pneumoniae in the concentration of $10^{4} \mathrm{cfu} / \mathrm{mL}$. The data are averages of at least three independent experiments and error bars indicate standard deviations. 



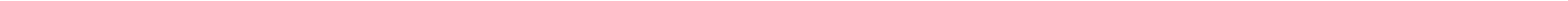




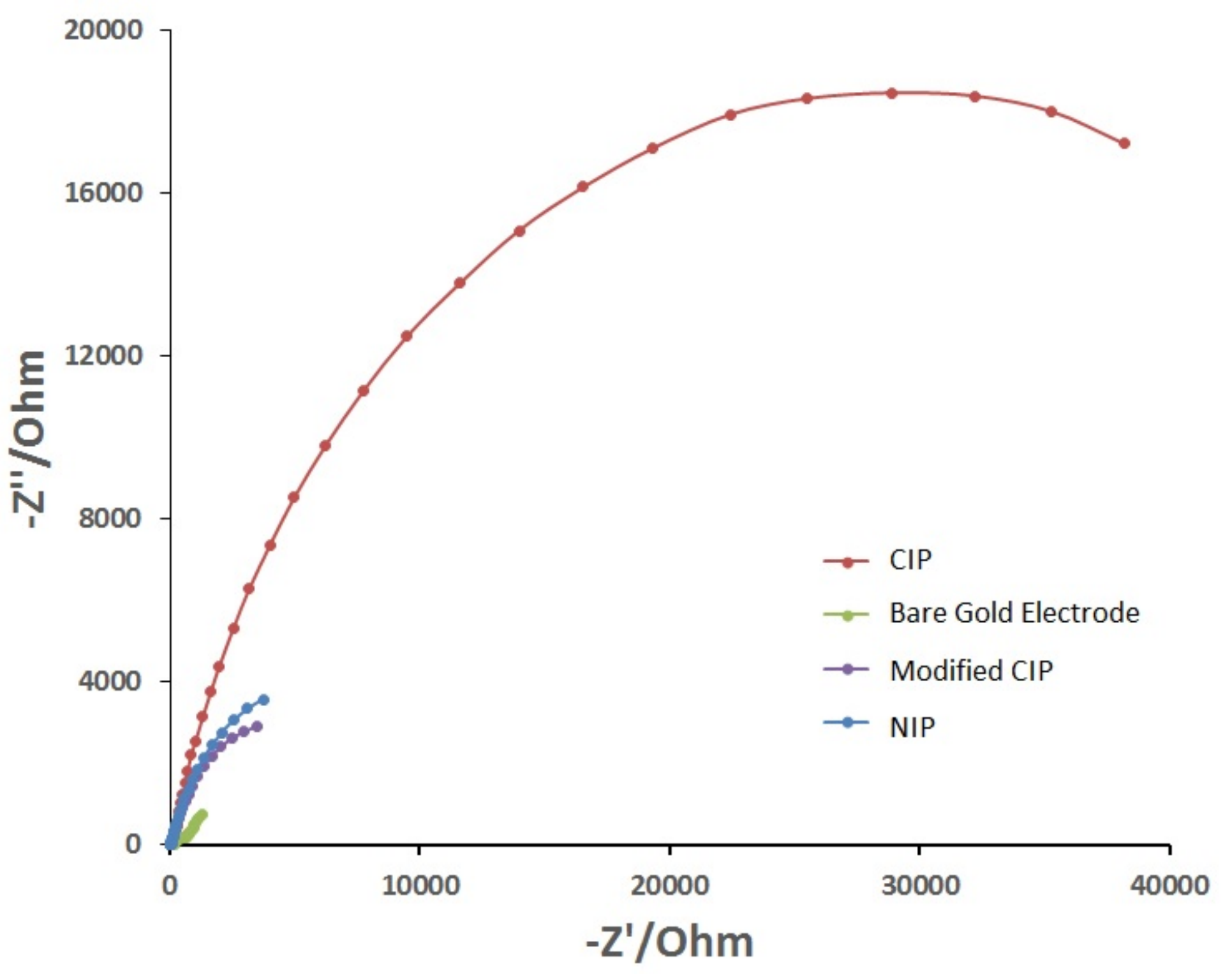




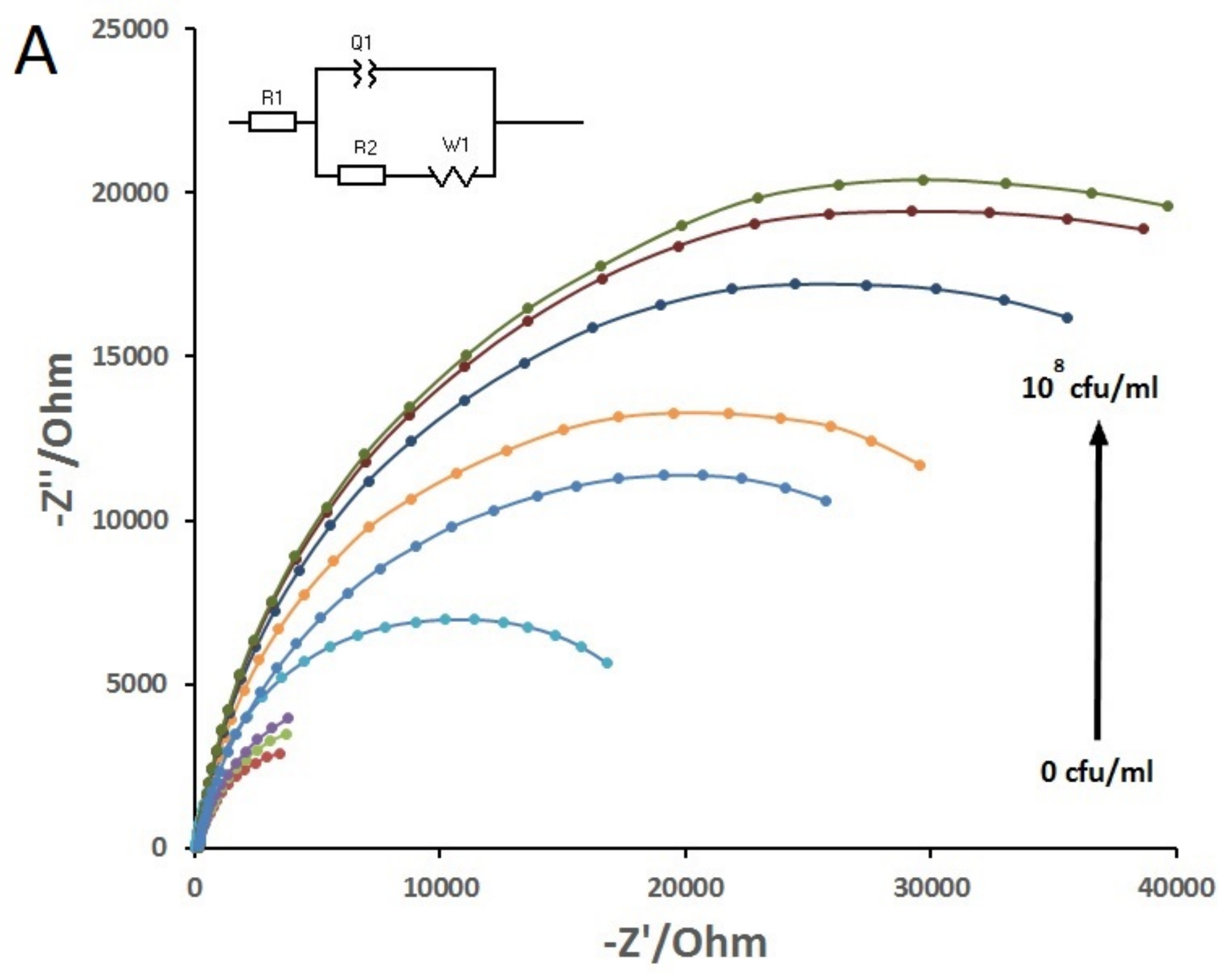




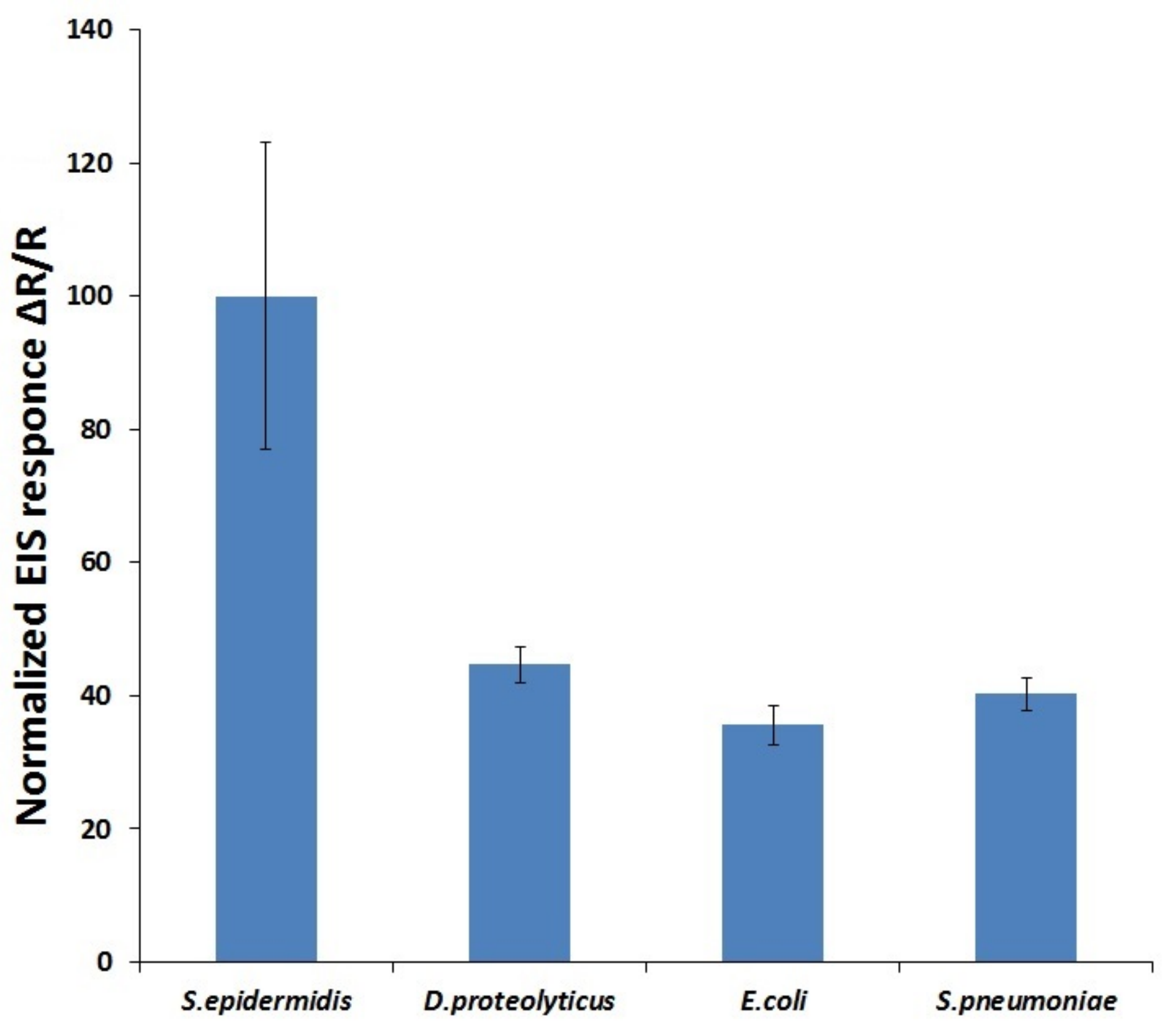




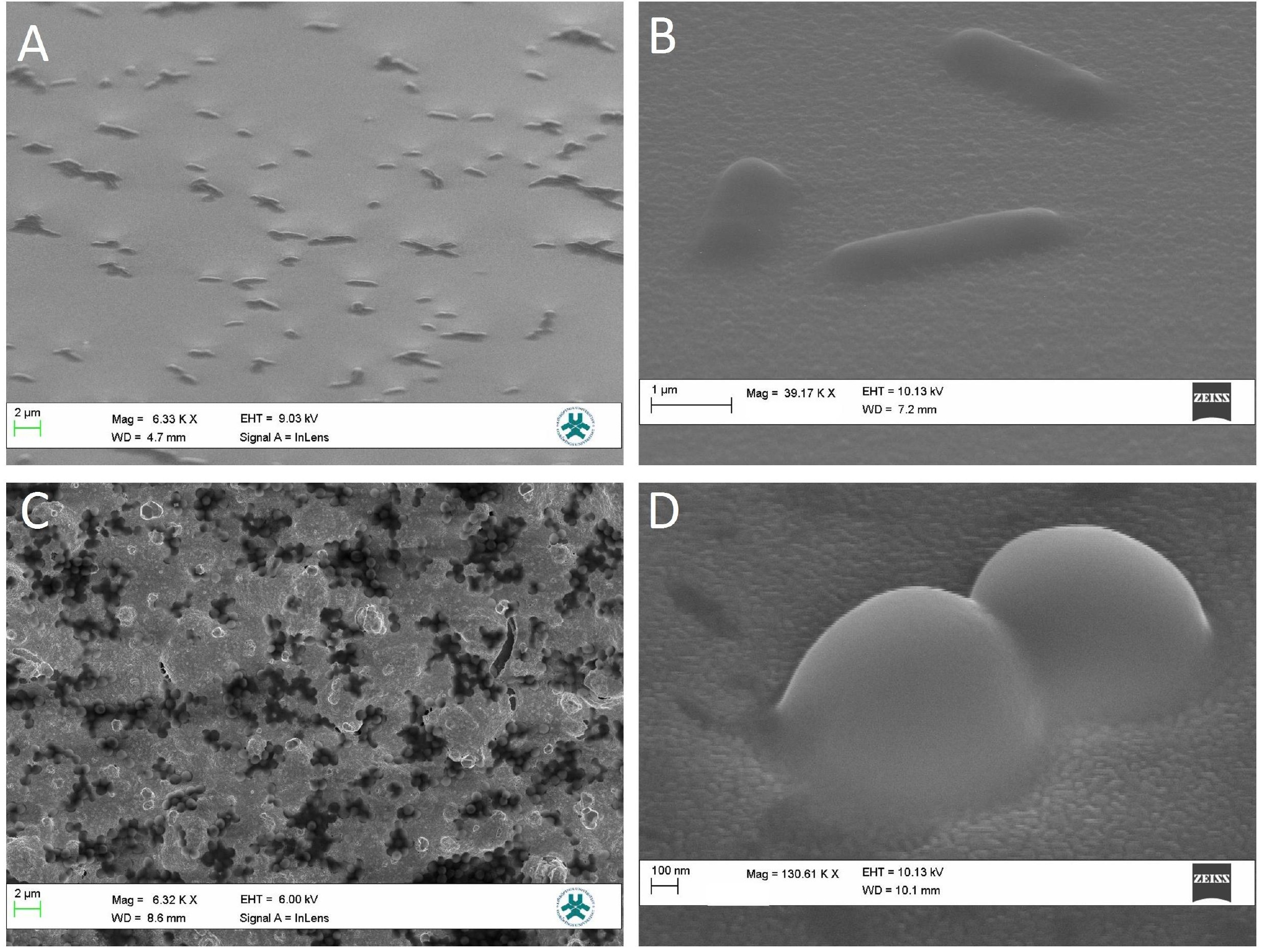




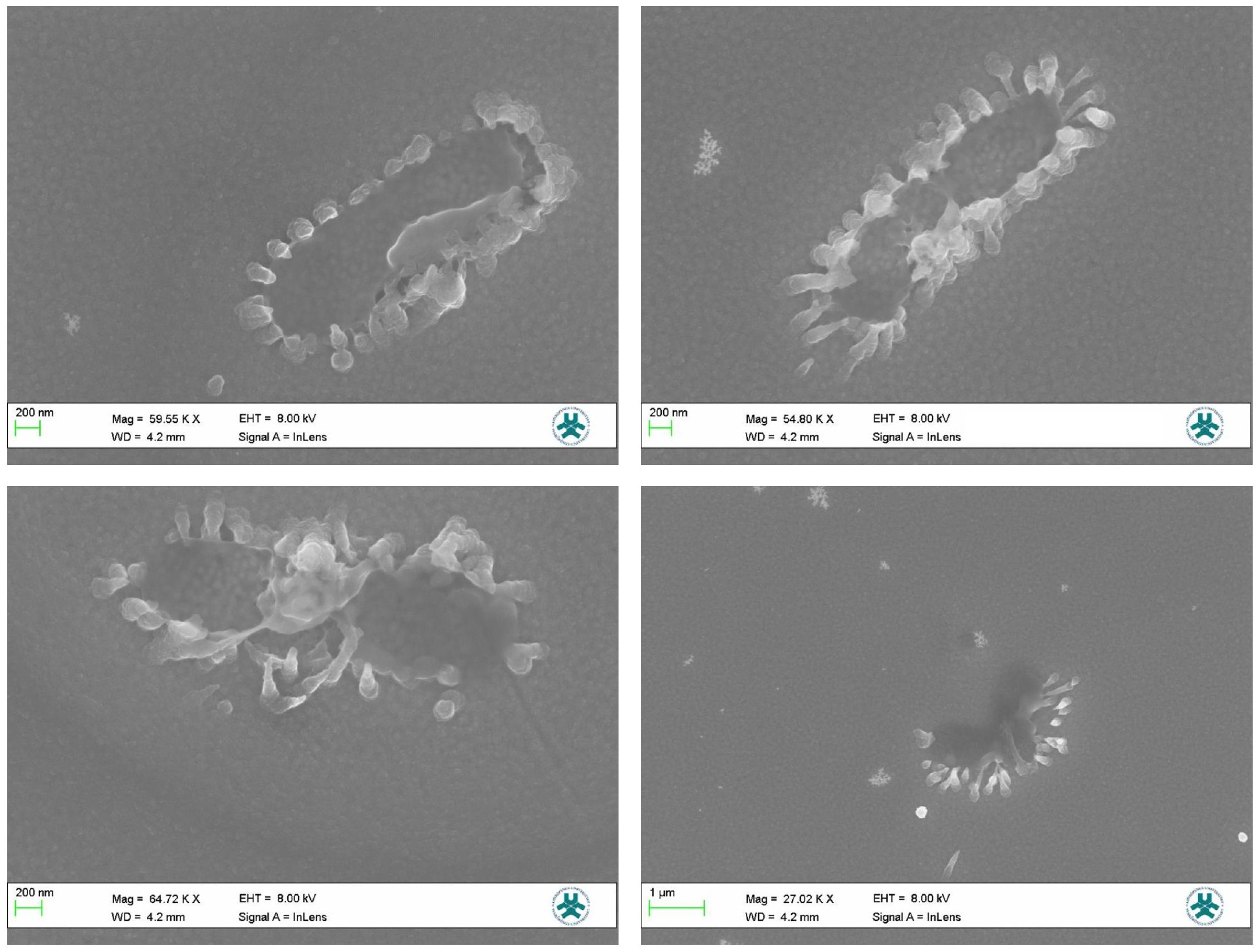



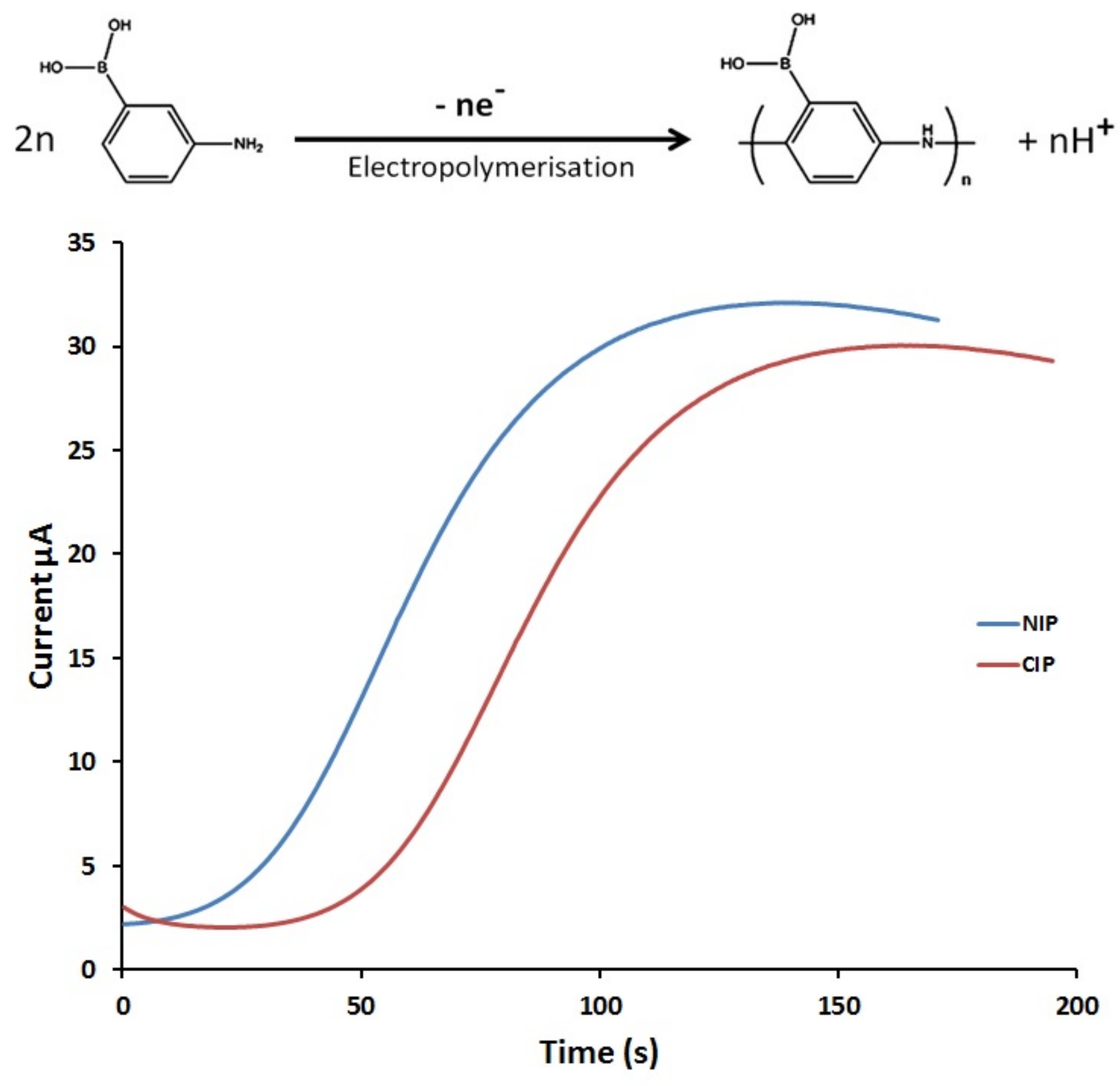


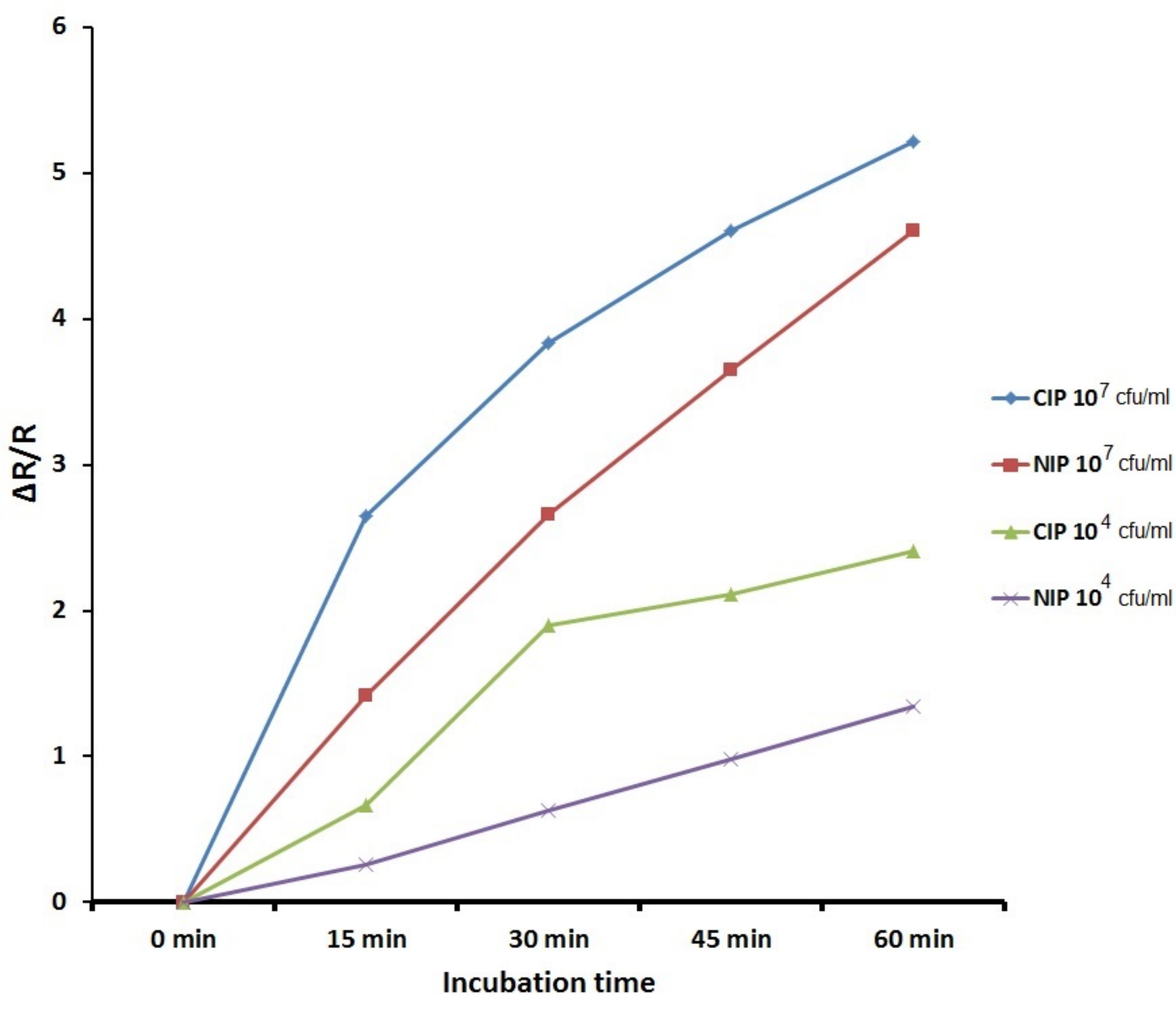

